\title{
Ayurvedic Companies on Consumer Behaviour
}

\author{
Shipra Gupta, Preeti Sharma
}

\begin{abstract}
The Indian FMCG is the fourth largest sector in the economy. In India, raw materials are cheaper and availability of labor are easy than other place. India may be got benefit in this worldwide competitive Era. Many numbers of ayurvedic companies are available in India. Few companies are maintaining their loyalty and believe in customers. Maximum countries of whole world appreciate the ayurvedic medicine of Indian companies. In this manuscript a questionnaire is filled by 50 respondents to know about the consumers' perception regarding mainly three Ayurveda company and their common brand. This questionnaire is fulfilled by different variables. After the analysis of this study it has been concluded that mostly consumers like the company Dabur and its product Chyawanprash. This manuscript will be very fruitful for the consumers and researchers.
\end{abstract}

Keywords: Ayurvedic companies, comparative study, product chyawanprash, consumers buying behavior.

\section{INTRODUCTION}

Dabur India Limited has a renowned presence for its momentous achievements started from 1884 by Burman family. Now its guidelines have a status of market leadership. The reason of the success of this company is due to its dedication to various aspects like: nature, corporate and process hygiene, dynamic leadership and fulfil its commitment with partners and stakeholders. Due to the above aspects this company has a separate entity. The main strategic business units of Dabur India Limited can divided into three divisions, these are Consumer Health Division, Consumer Care Division, International Business Division. This company has Dabur International, Fem Care Pharma and newu are the three main subsidiary group companies. This company has spread its ultra- modern manufacturing units around the world. The market area of this company is associated with more than sixty countries. This company has a wider and deep market by the association with a number of agents, distributors and retail outlet all around the whole world. This company is known by its loyalty more than 131 years. Now Dabur is the most popular Indian company famous for its quality and loyal brand. This company provides largest selling products in the world as Ayurevdic and Natural Health Care based.
Revised Manuscript Received on October 02, 2019.

Shipra Gupta, Associate Professor, Department of Commerce,

Graphic Era Hill University, Dehradun

Email: drshipragupta16@gmail.com

CA Preeti Sharma, Department of Commerce, Graphic Era Deemed to be University, Dehradun

\section{OBJECTIVES}

1. To know about the buying behavior of consumer.

2. Are the budget policies impacted to market strategy of this company?

\section{Scope of the study}

The present study analyzed the Marketing Strategy, consumer buying behavior and the problems faced by seasonal products of Dabur.

Data collection

The study is based on the primary data \& secondary data. The relevant and required data are collected through questionnaire which is filled by the correspondents.

\section{Sample size}

For this study, fifty consumers are selected. The consumers are of different ages and places._Plan of analysis

The researcher has used the statistical tools like percentage for analyzing the data. Percentage analysis is used to analyze the contribution of individual. It is used to analyze the result of the answers of the questionnaire.

products

1. Dabur Vatika - Premium hair care

2. Hajmola - Tasty digestives

3. Réal - Fruit juices \& beverages

4. Fem - Fairness bleaches \& skin care products

5. Dabur Chyawanprash - Health Care product

6. Honey - Food Product

7. Dabur Amla - Hair oil

8. Red Thoothpaste - Health Care

9. Lal Dant Manjan - Health Care

10. Glucose - Health Care

11. Odonil - Home Care

12. Babool - Personal Care

Objective of the study

1. Awareness of people through different variables for different company's chyawanprash.

2. Sources from which the respondents gets the knowledge about the innovative products.

\section{DATA ANALYSIS AND INTERPRETATION}

1. Age of Consumers: The age variables of Consumers regarding Chyawanprash shows that $12 \%$ consumers fall in the age group of 30-40 years, $20 \%$ fall in the age group of 41-50 years, $32 \%$ fall in 51-60 years and rest $36 \%$ are in the group of 60 years $\&$ above.

2. Education Status: The education status of Consumers regarding Chyawanprash shows that $10 \%$ consumers are illiterate, $20 \%$ get primary education, $38 \%$ are under graduates and rest $32 \%$ are graduates.

3. Occupation: Different type of occupation of Consumers regarding Chyawanprash shows

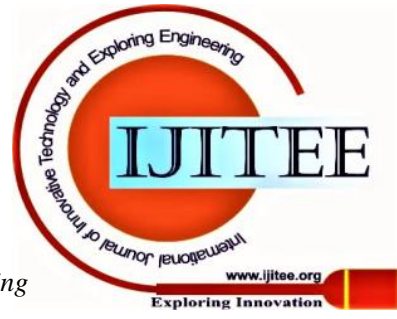




\section{Ayurvedic Companies on Consumer Behaviour}

that $24 \%$ consumers are doing agriculture, $34 \%$ are government employees, $16 \%$ aredoing private jobs and rest $26 \%$ are from other occupation.

4. Awareness of Different Brands: The awareness level of Consumers regarding Chyawanprash shows that $72 \%$ consumers are aware about Dabur, 12\% are aware about Baidyanath, $08 \%$ are aware about Zandu and rest $08 \%$ are aware about all the three.

5. Brand preferred by Consumers: The brand preferred by Consumers shows that $76 \%$ consumers prefer Dabur, $14 \%$ prefer Baidyanath and $10 \%$ prefer Zandu.

6. Reason To Choose the particular Brand: The reason why Consumers choose the particular brand. It shows that $36 \%$ consumers choose it because it healthy, $28 \%$ choose the brand because they are loyal to the particular brand, $20 \%$ of the respondents prefer it due to its taste and rest $16 \%$ due to price.

7. Satisfaction Level of Consumers: The satisfaction level of Consumers shows that $62 \%$ consumers are satisfied with Dabur, $16 \%$ are satisfied with Baidyanath and $22 \%$ are satisfied with Zandu.

8. Medium of Knowledge: The medium through which Consumers gets the knowledge of the brands shows that $70 \%$ consumers get knowledge through television, $22 \%$ get knowledge through newspaper and $08 \%$ get knowledge through internet.

9. Result of Unavailability: The result of unavailability of preferred brands shows that $46 \%$ consumers wait for the product, $36 \%$ purchase another brand \& $18 \%$ purchase whatever preferred by the retailer.

10. Preferred Size of Pack: The preferred size of the pack shows that $30 \%$ consumers purchase 250 gram pack, $48 \%$ consumers like to purchase 500 gram pack \& $22 \%$ consumers purchase $1 \mathrm{~kg}$ pack.

11. Reason for Preferred Pack size: The reason for preferred pack size of the Chyawanprash shows that $52 \%$ consumers purchase it due to availability, $24 \%$ consumers purchase it due to price, $12 \%$ due to family size \& $12 \%$ due to storage.

12. Frequency of Purchase: The reason for frequency of purchase the Ayurveda product Chyawanprash that $72 \%$ consumers purchase it monthly, 16\% consumers purchase it once in two months \& $12 \%$ purchase it once in 3 Months.

\section{FINDINGS}

From the above data, by variable 1 it has been concluded age variables of consumers of Dabur chyawanprash. There are the maximum number $36 \%$ consumers of Dabur chyawanprash are fall in the age group of 60 years and above. By variable 2 education status of Consumers of Dabur Chyawanprash, it shows that the maximum number $38 \%$ are under graduates those who are using this company product. Variable 3 shows the type of occupation of Consumers of Dabur Chyawanprash. It shows that the maximum number $34 \%$ are government employees. Variable 4 shows awareness level of Consumers of Dabur Chyawanprash. It shows that the maximum number $72 \%$ consumers are aware about Dabur. Variable 5 shows the brand preferred by Consumers. It shows that the maximum number $76 \%$ consumers prefer Dabur. Variable 6 shows the reason why Consumers choose the particular brand. It shows that the maximum number $36 \%$ consumers choose it because it healthy. Variable 7 shows the satisfaction level of Consumers. It shows that the maximum number $62 \%$ consumers are satisfied with Dabur. Variable 8 shows the medium through which Consumers gets the knowledge of the brands. It shows that the maximum number $70 \%$ consumers get knowledge through television. Variable 9 shows the result of unavailability of preferred brands. It shows that the maximum number $46 \%$ consumers wait for the product. Variable 10 shows the preferred size of the pack. It shows that the maximum number $48 \%$ consumers like to purchase 500 gram pack. Variable 11 shows the reason for preferred pack size. It shows that the maximum number $52 \%$ consumers purchase it due to availability. Variable 12 shows the reason for frequency of purchase. It shows that the maximum number $72 \%$ consumers purchase it monthly.

\section{SUGGESTIONS}

Company should be focused on the growth of other products range. Provide the complete knowledge about the product to the consumer. Company should take more initiative to enhance the visibility of the brand. Provide the new products with new features to the users within easy approach. As Dabur Chyawanprash is the seasonal Product that can be use only in winters, the new research can be undertaken so that new product can be launched in the market which can be consumed the whole year. It also helps in increasing sales of the particular product.

\section{CONCLUSION}

By the above analysis it has been concluded that many Ayurveda company and their one brand Chyawanprash has been tested by different aspects or variables by 50 respondents. These variables are verified by age, education status, occupation, awareness level, brand preference, reason for choosing the brand, satisfaction level of consumers, knowing about the medium of brand, result of unavailability of preferred brands, preferred size of the pack, reason for preferred pack size and reason for frequency of purchase the particular product by a chyawanprash user. After the study of these factors, we can say mostly consumers are preffered the company Dabur and its product Dabur Chyawanprash. So, Dabur Chyawanprash is one of the best product range of this company.

\section{REFERENCES}

1. Philip Kotler, Marketing Management ; Analysis Planning \& Control; Prentice Hall, 9th Edition.

2. Saxena Ranjan, Marketing Management; TATA Mcgraw Hill, 4th Edition, 2000.

3. Dr. R.L. Varshney \& Dr. S.L. Gupta, Marketing Management; An Indian Perspective; Sultan Chand \& Sons Education Publishers, New Delhi; 2nbd Ed. 2001.

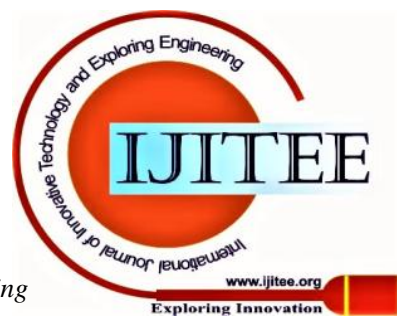


4. Consumers and Their Brands: Developing Relationship Theory in Consumer Research, 1998, Susan Fournier.

5. Assessing Measurement Invariance in Cross-National Consumer Research, 1998, Jan-Benedict E. M. Steen amp and Hans Baumgartner.

6. Constructive Consumer Choice Processes, 1998, James R. Bettman, Mary Frances Luce, and John W. Payne.

7. A Model of Customer Satisfaction With Service Encounters Involving Failure and Recovery, 1999, Amy K. Smith, Ruth N. Bolton, and Janet Wagner

8. Satisfaction, Repurchase Intent, and Repurchase Behavior: Investigating the Moderating Effect of Customer Characteristics, 2001, Vikas Mittal and Wagner A. Kamakura

9. A Dynamic Model of Customers, Usage of Services: Usage as an Antecedent and Consequence of Satisfaction, 1999, Ruth N. Bolton and Katherine N. Lemon.

10. Building Brand Image Through Event Sponsorship: The Role of Image Transfer, 1999, K. P. Gwinner and J. Eaton.

11. The Impact of Corporate Credibility and Celebrity Credibility on Consumer Reaction to Advertisements and Brands, 2000, R. E. Goldsmith, B. A. Lafferty, and S. J. Newell.

12. Impact of 3-D Advertising on Product Knowledge, Brand Attitude, and Purchase Intention: The Mediating Role of Presence, 2002, Hairong Li, Terry Daugherty, and Frank Biocca.

13. Buboltz, W. C., Jr., Miller, M., \& Williams, D. J. (1999). Content analysis of research in the Journal of Counseling Psychology.

14. Howard, J., \& Sheth, J. N. (1968). The theory of buyer behavior. New York, NY: John Wiley.

15. Kassarjian, H. H. (1977). Content analysis in consumer research. Journal of Consumer Research, 4, 8-18.

16. www.google.com

17. Wikipedia

18. www.dabur.com 